\title{
Erratum
}

\section{Boundary Assessment Under Uncertainty: A Case Study}

The deletion of an illustration from our manuscript during the review process unfortunately resulted in a few errors (Pawlowsky, Olea, and Davis, 1993). Fig. 8 in our paper shows water saturation, $S_{w}$, and should have been omitted. The correct Fig. 8 is given here and is a map of average porosity, as described in the original figure caption.

The two following figure captions also are incorrect. The captions should read:

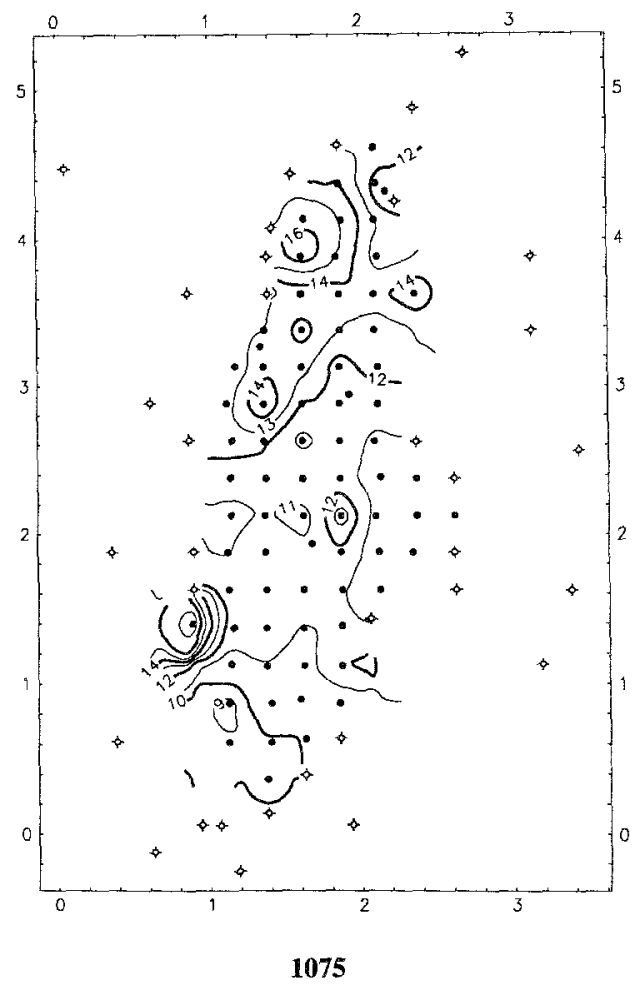


Fig. 9. Contour map of average oil saturation obtained as the difference between a map $S_{w}$ and a map of uniform values of 100 . Contours in percent of pore volume.

Fig. 10. Contour map of average oil saturation expressed as percent of rock volume obtained as the product of Figs. 8 and 9.

\section{REFERENCE}

Pawlowsky, V., Olea, R. A., and Davis, J. C., 1993, Boundary Assessment Under Uncertainty: A Case Study: Math. Geol., v. 25, n. 2, p. 125-144.

\section{Vera Pawlowsky}

Departament de Matemática Aplicada III

Universitat Politècnica de Catalunya

Avda. Gran Capità, s/n

E-08034 Barcelona

Spain

Ricardo A. Olea and John C. Davis

Kansas Geological Survey

1930 Constant Avenue

Lawrence, Kansas 66047 